\title{
Growth of transgenic RAF-induced lung adenomas is increased in mice with a disrupted PPARß/ס gene
}

\author{
SABINE MÜLLER-BRÜSSELBACH ${ }^{1}$, SCHOKUFE EBRAHIMSADE ${ }^{2}$, JÖRG JÄKEL ${ }^{2}$, JENNY ECKHARDT ${ }^{1}$, \\ ULF R. RAPP $^{3}$, JEFFREY M. PETERS ${ }^{4}$, ROLAND MOLL $^{2}$ and ROLF MÜLLER ${ }^{1}$ \\ ${ }^{1}$ Institute of Molecular Biology and Tumor Research (IMT), Philipps University, Emil-Mannkopff-Strasse 2, D-35032 Marburg; \\ ${ }^{2}$ Department of Pathology, Philipps University, Baldingerstr., D-35043 Marburg; ${ }^{3}$ MSZ, University of Würzburg, \\ Versbacher Str. 5, D-97078 Würzburg, Germany; ${ }^{4}$ Department of Veterinary and Biomedical Sciences \\ and Center for Molecular Toxicology and Carcinogenesis, 312 Life Sciences Building, \\ The Pennsylvania State University, University Park, PA 16802, USA
}

Received March 28, 2007; Accepted May 30, 2007

\begin{abstract}
Peroxisome proliferator-activated receptors (PPARs) are ligand-activated transcription factors with essential functions in regulating lipid metabolism. Both the PPARß (also referred to as PPAR $\delta$ ) and PPAR $\gamma$ subtype have been reported to either attenuate or potentiate tumorigenesis in a number of different models of intestinal and skin carcinogenesis. In the present study, we have addressed the role of PPARß and PPAR $\gamma$ in lung tumorigenesis in a transgenic mouse model of RAF-induced lung adenoma using two different strategies: i) crossing with PPARß null mice, and ii) chronic treatment with the PPAR $\gamma$ agonist rosiglitazone. Histological examination revealed a significant enhancement of tumor growth in mice lacking one or both alleles of Pparb, but no significant effect in response to rosiglitazone. These observations indicate i) that RAF-induced lung tumorigenesis is attenuated in mice with a disrupted Pparb gene, and ii) that chronic PPAR $\gamma$ activation does not affect lung adenoma growth. These results are relevant with respect to the clinical application of drugs modulating the activity of PPARß or $\operatorname{PPAR} \gamma$.
\end{abstract}

\section{Introduction}

Peroxisome proliferator-activated receptors (PPARs) are transcription factors of the class of nuclear receptors that modulate target gene expression in response to endogenous and exogenous ligands (1-6). The PPAR family consists of

Correspondence to: Dr Rolf Müller, Institute of Molecular Biology and Tumor Research (IMT), Philipps University, Emil-MannkopffStrasse 2, D-35032 Marburg, Germany

E-mail: rmueller@imt.uni-marburg.de

Key words: peroxisome proliferator-activated receptors, lung tumorigenesis, rosiglitazone

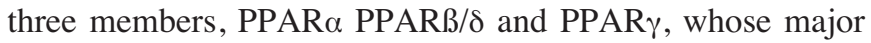
physiological functions are associated with the regulation of lipid metabolism. Intriguingly, all PPAR subtypes have also been associated with tumorigenesis. While PPAR $\alpha$ has a species-specific role in rodent hepatocarcinogenesis, PPARß and PPAR $\gamma$ have been implicated in a number of different types of cancer. Consistent with the physiological function of PPARß in cell proliferation and differentiation in diverse cell types, including keratinocytes (7-9), trophoblastic cells (10) and intestinal epithelial cells (11), a role for PPARß in chemically-induced skin carcinogenesis (12) and intestinal tumorigenesis (13-17) have also been described, although its precise function remains controversial. PPAR $\gamma$ is of major biomedical interest, since it is the target of the thiazolidinedione anti-diabetic drugs (such as rosiglitazone), and also because it is able to exert anti-oncogenic effects in diverse model systems. Activation of PPAR $\gamma$ inhibits tumor cell proliferation in vitro, suppresses tumor growth in mouse models and induces tumor cell apoptosis in vivo and in vitro (reviewed in refs. 18,19). However, similar to the function of PPAR 3 in carcinogenesis, there are also inconsistent reports suggesting that PPAR $\gamma$ may potentiate tumorigenesis as well. For example, administration of the PPAR $\gamma$ agonists BRL-49,653 and troglitazone to $\mathrm{Apc}^{\mathrm{Min}}$ mice paradoxically enhances the formation of intestinal polyps $(20,21)$. Further, the targeted disruption of Pparg in mammary epithelium has no effect on tumor incidence (22). The role of PPARs using in vivo lung tumor models has not been analyzed to date. In the present study, we report the effects of modulating PPAR $\beta$ or PPAR $\gamma$ activity in a transgenic mouse model of RAF-induced lung adenoma.

\section{Materials and methods}

Mouse experiments. Pparb ${ }^{-/}$mice (12) and c-Raf-1-BxB (23) mice have been previously described. All experiments were performed with mice backcrossed with the C57BL/6N strain. Genotyping was performed by PCR. Rosiglitazone maleate (Avandia, Glaxo-Smith Kline-Beecham) was suspended in water and applied to mice per os at a dose of $30 \mathrm{mg} / \mathrm{kg}$ body 
Table I. Primers and annealing conditions.

\begin{tabular}{llccc}
\hline Mouse gene & \multicolumn{1}{c}{ Sequence $5^{\prime} \rightarrow 3^{\prime}$} & Length $(\mathrm{nt})$ & Product $(\mathrm{bp})$ & Annealing $\left({ }^{\circ} \mathrm{C}\right)$ \\
\hline Pparb & CCTCCATCGTCAACAAAGACG & 21 & 377 & 60 \\
& TTTAGCCACTGCATCATCTGGGCATGCTC & 29 & & \\
\multirow{2}{*}{ L27 } & AAAGCCGTCATCGTGAAGAAC & 21 & 58 \\
& GCTGTCACTTTCCGGGGATAG & 21 & \\
\hline
\end{tabular}

$L 27$ was used as the normalizer. Results were expressed as $\mathrm{C}_{\mathrm{t}}$ values corrected for differences in $L 27$ expression (average $\mathrm{C}_{\mathrm{t}}$ value $L 27=20$ ).

weight once per day (24). Treatment was started at the age of 4 weeks and was continued for another 2 months until the end of the experiment.

Histological evaluation. Lungs were fixed in neutral buffered $10 \%$ formalin for $24 \mathrm{~h}$ and embedded in paraffin. Hematoxylineosin stained sections (3-4- $\mu \mathrm{m}$ thick) were viewed under a light microscope. Tumor nodules were identified as nodules of cuboid epithelial cells containing slightly enlarged and minimally atypical nuclei (23) some of which exhibited intranuclear inclusions. Tumors were classified according to their size into: i) small tumors (diameter corresponding to that of 1-2 average alveolar lumina), ii) intermediate-size tumors (diameter corresponding to 3-5 average alveolar luminal diameters), and iii) large tumors (diameter exceeding 5 average alveolar luminal diameters). For each animal, one section through one lung was used for morphological analysis and counting of the tumor nodules. For an assessment of the tumor load per lung, a tumor score was defined which was calculated according to the following formula: Score = tumor nodules per lung $\times \mathrm{F}$, where $\mathrm{F}=1$ for small tumors, $\mathrm{F}=2$ for intermediate-size tumors and $\mathrm{F}=3$ for large tumors. The total area (including air spaces) of the lung tissue sections evaluated was measured morphometrically (Image-Pro Plus; Media Cybernetics, Silver Spring, MA, USA). Tumor numbers and tumor score values were related to the evaluated lung tissue area.

RNA isolation. RNA was isolated using the RNeasy ${ }^{\mathrm{TM}}$ kit (Qiagen, Hilden, Germany) following the manufacturer's protocol. Qia shredders (Qiagen) were used to break down genomic DNA of lysed cells.

Real-time PCR ( $q P C R)$. cDNA was synthesized using $1 \mu \mathrm{g}$ of RNA, oligo(dT) primers and reverse transcriptase according to the manufacturer's protocol (Roche Diagnostics). qPCR reactions were carried out using the Absolute QPCR SYBR Green Mix (Abgene, Hamburg, Germany) at a primer concentration of $0.2 \mu \mathrm{M}$ in a Mx3000P Real-Time PCR system (Stratagene, La Jolla, CA) for 45 cycles. Primers and annealing conditions were as described in Table I.

\section{Results}

Effect of Pparb disruption of RAF-induced lung tumors. c-Raf$1-\mathrm{BxB}$ mice have an activated C-RAF transgene driven by the surfactant protein-C (SP-C) promoter (23). These mice develop multiple benign adenomas in type II pneumocytes within 3 months after birth (23). We used this strain to investigate whether PPARß plays a role in lung cancer. The c-Raf-1-BxB is of particular interest in this context, since previous studies have shown that PPARß expression can be induced by the Ras-RAF-Erk signaling pathway in different cell types in vitro $(25,26)$.

To study the role of PPARß in RAF-induced lung cancer we crossed c-Raf-1-BxB onto a Pparb ${ }^{-1-}$ background. The $\mathrm{Pparb}^{-/}$mice used for this experiment harbor a phosphoribosyltransferase II expression cassette in the last exon of the Pparb gene resulting in a lack of PPARß protein expression $(12,14)$. c-Raf-1-BxB and $P_{p a r b}{ }^{-/}$mice were crossed to obtain transgenic c-Raf-1-BxB positive mice on different $P P A R b$ genetic backgrounds. Pparb wild-type, Pparb ${ }^{+/}$and Pparb ${ }^{-/-}$ were analyzed for lung tumor development $(\mathrm{n}=28)$. Histological examination revealed a clearly increased incidence of lung adenomas in both Pparb $^{+/-}$and Pparb ${ }^{-/-}$mice. While the average tumor incidence in Pparb wild-type mice was $1.37 \pm 0.45$ nodules $/ \mathrm{mm}^{2}$, this was increased to $2.95 \pm 1.53$ in Pparb $^{+/-}$mice and 2.72 \pm 0.92 in Pparb ${ }^{-/}$mice. These differences are statistically highly significant (wild-type versus heterozygous: $\mathrm{P}=0.010$; wild-type versus null: $\mathrm{P}=0.002$; Fig. $1 \mathrm{~A}$ ).

We also defined a tumor score taking the tumor size into account (for details see Materials and methods). Similarly, a significant increase was observed in both Pparb $^{+/-}$and Pparb ${ }^{-/-}$ mice: the average tumor score was $2.85 \pm 0.97$ in $P$ parb wildtype mice, which was increased to $6.17 \pm 3.15$ and $6.43 \pm 2.45$ in Pparb $^{+/-}$and Pparb $^{-/}$mice, respectively (wild-type versus heterozygous: $\mathrm{P}=0.009$; wild-type versus null: $\mathrm{P}=0.002$; Fig. 1B). We analyzed lungs both of 3 and 6 months old mice with essentially the same result (not shown). These data clearly indicate that PPARß attenuates the growth of C-RAF induced lung adenomas, similarly to the inhibitory effect of PPARß in intestinal adenoma $(14,17)$.

Pparb has been described as a target gene of the RAS pathway in cultured intestinal epithelial cells and fibroblasts $(25,26)$. To determine whether Pparb expression was elevated in c-Raf-1-BxB lungs in vivo, we performed qPCR analysis to quantify mRNA transcripts for PPARß. No differences in Pparb mRNA were detectable in lungs from c-Raf-1-BxB mice compared to $C-R A F$ transgene negative mice, indicating that RAF signaling does not regulate Pparb expression in alveolar cells in vivo (Fig. 2). 
A

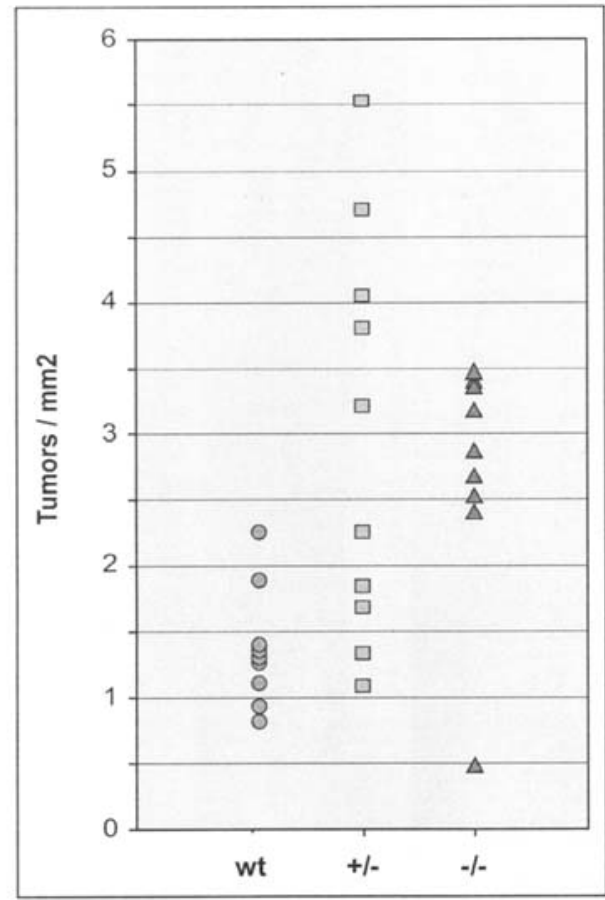

B

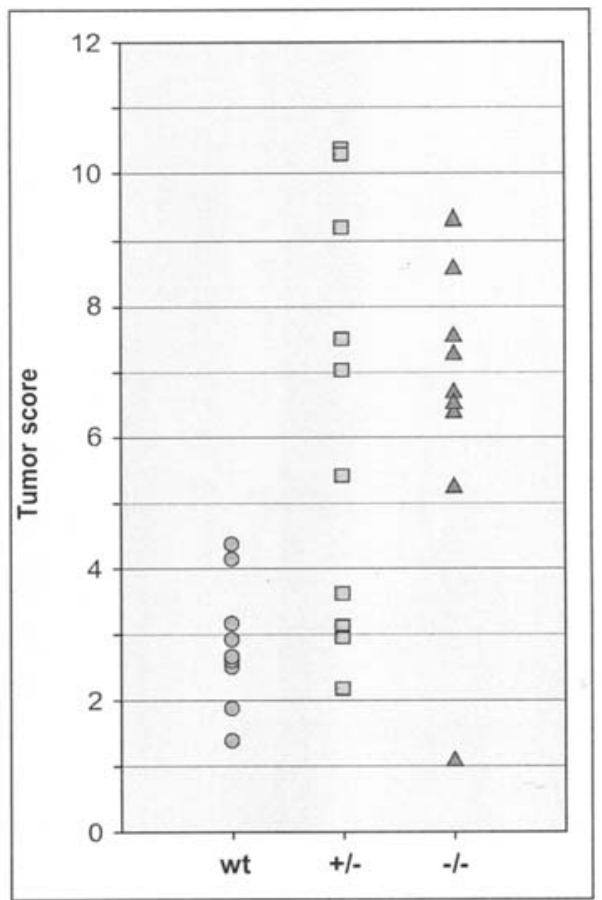

Figure 1. Growth of RAF-induced lung adenomas in mice with an altered genetic status of Pparb. Tumor incidence (A, expressed as nodules/mm²) and tumor score (B, for details see Materials and methods) were determined microscopically in c-Raf-1-BxB mice on a Pparb wt, Pparb ${ }^{+/-}$and Pparb ${ }^{-/}$background.

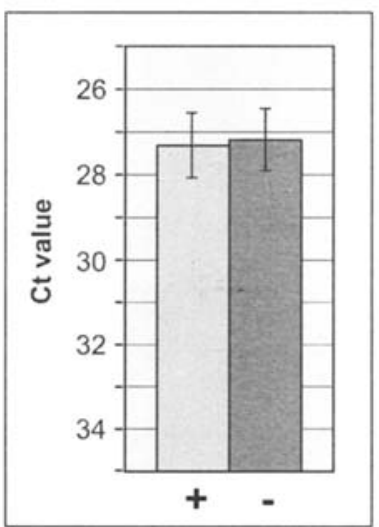

Figure 2. Expression of Pparb in lung tissue from c-Raf-1-BxB transgene positive (+) and negative (-) mice. Pparb expression was determined by qPCR. Data are represented as $C_{t}$ values normalized to L27 RNA levels.

Effect of PPAR activation on RAF-induced lung tumors. In most experimental systems used to date, PPAR $\gamma$ inhibits tumorigenesis, e.g. by inhibiting tumor cell proliferation and inducing apoptosis (reviewed in refs. 18,19). However, there are other findings that are inconsistent with this view including the observation that $\mathrm{Apc}^{\mathrm{Min}}$ mice treated with a PPAR $\gamma$ agonist exhibit increased intestinal adenoma growth $(20,21)$. To evaluate whether a PPAR $\gamma$ agonist would influence the growth of lung adenomas in c-Raf-1-BxB mice, rosiglitazone maleate was administered orally to Raf-1-BxB mice for a period of 2 months $(30 \mathrm{mg} / \mathrm{kg} / \mathrm{d})$ essentially as described (24). The experiment was initiated at the age of 4 weeks when lung tumors in Raf-1-BxB mice were just beginning to become microscopically detectable. At the end of the experiment, mice were euthanized, and tumor incidence and tumor score were determined as above. Neither tumor incidence $(\mathrm{P}=0.78)$ nor tumor score $(\mathrm{P}=0.87)$ showed any significant difference among treated and untreated mice (Fig. 3). We also measured expression of the PPAR $\gamma$ target gene $C D 36$ and found a significant induction in rosiglitazone treated animals, demonstrating that the treatment regimen was effective at the molecular level (data not shown). These data indicate that in contrast to intestinal carcinogenesis, chronic PPAR $\gamma$ activation has no influence on lung adenoma growth.

\section{Discussion}

The present studies investigated the role of PPAR $B$ and PPAR $\gamma$ in RAF-induced lung tumorigenesis using two different approaches: the genetic disruption of Pparb and the administration of the PPAR $\gamma$ agonist rosiglitazone. Previous reports suggested that PPARß can either attenuate or potentiate tumorigenesis in a number of different models (reviewed in ref. 27). Results from the present study indicate that PPARß is not required, but rather has an inhibitory effect on C-RAFinduced lung cancer. This is consistent with reports showing that PPARß is dispensable for, or inhibitory to, intestinal tumorigenesis in both $\operatorname{APC}^{\mathrm{Min}}$ mice $(13,14)$ and a mouse model based on a defect in mismatch DNA repair (28). Our observations are consistent with previous findings showing that PPAR $\beta$ regulates terminal differentiation and has a negative regulatory role in the proliferation of certain cell 
A

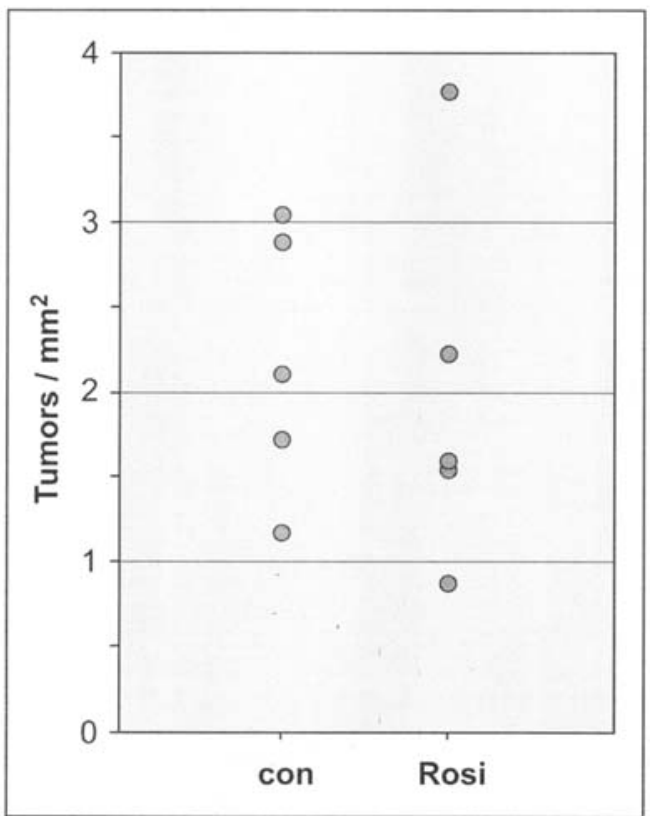

B

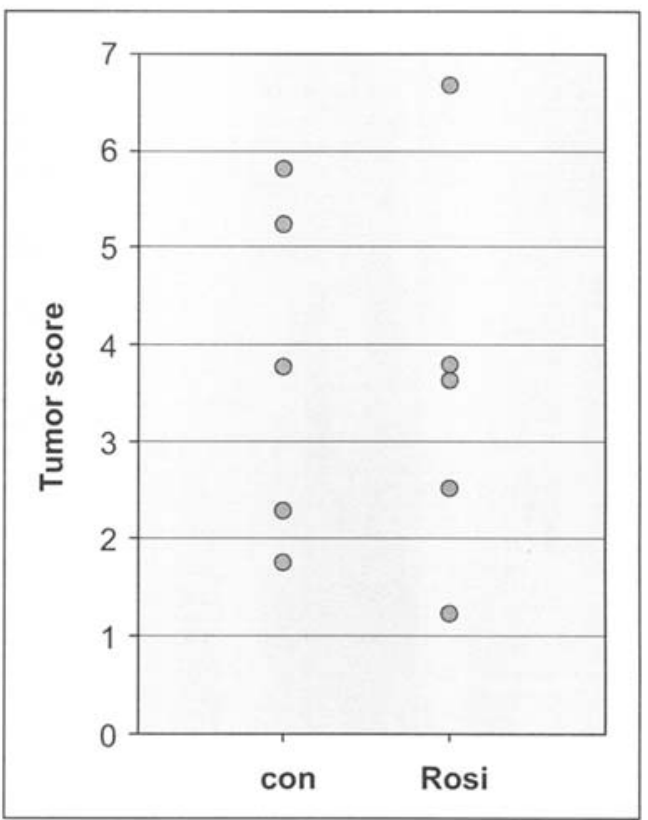

Figure 3. Effect the PPAR $\gamma$ agonist rosiglitazone on the growth of RAF-induced lung adenomas. Effect of PPAR $\gamma$ activation on lung adenoma growth. Tumor incidence (A, expressed as nodules $/ \mathrm{mm}^{2}$ ) and tumor score (B, for details see Materials and methods) were determined in untreated c-Raf-1-BxB mice (con) and in mice treated with the PPAR $\gamma$ agonist rosiglitazone (Rosi) for 2 months at a dose of $30 \mathrm{mg} / \mathrm{kg} / \mathrm{d}$.

types, including keratinocytes (7-9), trophoblast giant cells (10) and intestinal epithelial cells (11). Collectively, these findings suggest that PPARß is unlikely to possess prooncogenic properties, but rather seems to have a negative regulatory role in tumor growth. This is important in view of ongoing efforts to develop PPARß agonists for the treatment of metabolism-related human diseases, in particular in view of disparate results regarding the effect of such drugs on intestinal adenoma growth in the mouse $(16,17)$.

In contrast, administration of the PPAR $\gamma$ ligand rosiglitazone had no detectable influence on C-RAF-induced lung carcinogenesis. This is consistent with previous findings that the genetic status of Pparg has no effect on mammary tumor development in mice (22). On the other hand, other reports suggest that PPAR $\gamma$ can inhibit tumorigenesis-related processes in lung cancer model systems in cell culture (reviewed in ref. 19). Different explanations may account for this disparity, in particular differences in the model system used (in vivo versus in vitro) and differences in the oncogenic alterations mediating the carcinogenic effect. It thus remains possible that ligand activation of PPAR $\gamma$ could modulate lung carcinogenesis triggered by other oncogenic signaling pathways, as suggested by the paradoxical exacerbation of intestinal tumorigenesis by PPAR $\gamma$ agonists in $\operatorname{Apc}^{\mathrm{Min}}$ mice $(20,21)$. Alternatively, or additionally, the role of PPAR $\gamma$ in carcinogenesis is cell type-specific. Finally, PPAR $\gamma$ independent effects by PPAR $\gamma$ agonists on gene expression, cell proliferation and apoptosis have been described in several studies (29-35), including the inhibition of translation initiation through inactivation of eukaryotic initiation factor 2 (eIF2) (29) which might explain some of the anti-oncogenic effects of this class of PPAR $\gamma$ agonists and question the mechanistic interpretation of a number of published studies. Clearly, more experimental work on defined systems is required to clarify the role of PPAR $\gamma$ in tumor development and growth. This is particularly relevant with respect to the development and clinical application of drugs modulating the activity of $\operatorname{PPAR} ß$ or PPAR $\gamma$.

\section{Acknowledgements}

We are grateful to Julia Dick, Margitta Alt and Bernard Wilke for excellent technical assistance. This work was supported by grants from the Wilhelm-Sander-Stiftung, the Deutsche Krebshilfe and the Deutsche Forschungsgemeinschaft (SFBTR17).

\section{References}

1. Desvergne B and Wahli W: Peroxisome proliferator-activated receptors: nuclear control of metabolism. Endocr Rev 20: 649-688, 1999.

2. Berger $\mathbf{J}$ and Moller DE: The mechanisms of action of ppars. Annu Rev Med 53: 409-435, 2002.

3. Lee $\mathrm{CH}$, Olson P and Evans RM: Minireview: lipid metabolism, metabolic diseases, and peroxisome proliferator-activated receptors. Endocrinology 144: 2201-2207, 2003.

4. Evans RM, Barish GD and Wang YX: Ppars and the complex journey to obesity. Nat Med 10: 355-361, 2004.

5. Feige JN, Gelman L, Michalik L, Desvergne B and Wahli W: From molecular action to physiological outputs: Peroxisome proliferator-activated receptors are nuclear receptors at the crossroads of key cellular functions. Prog Lipid Res 45: 120-159, 2006.

6. Desvergne B, Michalik L and Wahli W: Transcriptional regulation of metabolism. Physiol Rev 86: 465-514, 2006.

7. Tan NS, Michalik L, Noy N, Yasmin R, Pacot C, Heim M, Fluhmann B, Desvergne B and Wahli W: Critical roles of ppar beta/delta in keratinocyte response to inflammation. Genes Dev 15: 3263-3277, 2001. 
8. Schmuth M, Haqq CM, Cairns WJ, Holder JC, Dorsam S, Chang S, Lau P, Fowler AJ, Chuang G, Moser AH, Brown BE, Mao-Qiang M, Uchida Y, Schoonjans K, Auwerx J, Chambon P, Willson TM, Elias PM and Feingold KR: Peroxisome proliferatoractivated receptor (ppar)-beta/delta stimulates differentiation and lipid accumulation in keratinocytes. J Invest Dermatol 122: 971-983, 2004.

9. Kim DJ, Bility MT, Billin AN, Willson TM, Gonzalez FJ and Peters JM: Pparbeta/delta selectively induces differentiation and inhibits cell proliferation. Cell Death Differ 13: 53-60, 2006.

10. Nadra K, Anghel SI, Joye E, Tan NS, Basu-Modak S, Trono D, Wahli W and Desvergne B: Differentiation of trophoblast giant cells and their metabolic functions are dependent on peroxisome proliferator-activated receptor beta/delta. Mol Cell Biol 26: 3266-3281, 2006

11. Varnat F, Heggeler BB, Grisel P, Boucard N, Corthesy-Theulaz I, Wahli W and Desvergne B: Pparbeta/delta regulates paneth cell differentiation via controlling the hedgehog signaling pathway. Gastroenterology 131: 538-553, 2006.

12. Peters JM, Lee SS, Li W, Ward JM, Gavrilova O, Everett C, Reitman ML, Hudson LD and Gonzalez FJ: Growth, adipose, brain, and skin alterations resulting from targeted disruption of the mouse peroxisome proliferator-activated receptor beta(delta). Mol Cell Biol 20: 5119-5128, 2000.

13. Barak Y, Liao D, He W, Ong ES, Nelson MC, Olefsky JM, Boland R and Evans RM: Effects of peroxisome proliferatoractivated receptor delta on placentation, adiposity, and colorectal cancer. Proc Natl Acad Sci USA 99: 303-308, 2002.

14. Harman FS, Nicol CJ, Marin HE, Ward JM, Gonzalez FJ and Peters JM: Peroxisome proliferator-activated receptor-delta attenuates colon carcinogenesis. Nat Med 10: 481-483, 2004.

15. Reed KR, Sansom OJ, Hayes AJ, Gescher AJ, Winton DJ, Peters JM and Clarke AR: Ppardelta status and apc-mediated tumourigenesis in the mouse intestine. Oncogene 23: 8992-8996, 2004.

16. Gupta RA, Wang D, Katkuri S, Wang H, Dey SK and DuBois RN: Activation of nuclear hormone receptor peroxisome proliferatoractivated receptor-delta accelerates intestinal adenoma growth. Nat Med 10: 245-247, 2004.

17. Marin HE, Peraza MA, Billin AN, Willson TM, Ward JM, Kennett MJ, Gonzalez FJ and Peters JM: Ligand activation of peroxisome proliferator-activated receptor beta inhibits colon carcinogenesis. Cancer Res 66: 4394-4401, 2006.

18. Müller R: Crosstalk of oncogenic and prostanoid signaling pathways. J Cancer Res Clin Oncol 130: 429-444, 2004.

19. Peraza MA, Burdick AD, Marin HE, Gonzalez FJ and Peters JM: The toxicology of ligands for peroxisome proliferator-activated receptors (ppar). Toxicol Sci 90: 269-295, 2006.

20. Lefebvre AM, Chen I, Desreumaux P, Najib J, Fruchart JC, Geboes K, Briggs M, Heyman R and Auwerx J: Activation of the peroxisome proliferator-activated receptor gamma promotes the development of colon tumors in $\mathrm{c} 57 \mathrm{bl} / 6 \mathrm{j}-\mathrm{apcmin} /+$ mice. Nat Med 4: 1053-1057, 1998.

21. Saez E, Tontonoz P, Nelson MC, Alvarez JG, Ming UT, Baird SM, Thomazy VA and Evans RM: Activators of the nuclear receptor ppargamma enhance colon polyp formation. Nat Med 4: 1058-1061, 1998.
22. Cui Y, Miyoshi K, Claudio E, Siebenlist UK, Gonzalez FJ, Flaws J, Wagner KU and Hennighausen L: Loss of the peroxisome proliferation-activated receptor gamma (ppargamma) does not affect mammary development and propensity for tumor formation but leads to reduced fertility. J Biol Chem 277: 17830-17835, 2002.

23. Kerkhoff E, Fedorov LM, Siefken R, Walter AO, Papadopoulos T and Rapp UR: Lung-targeted expression of the c-raf-1 kinase in transgenic mice exposes a novel oncogenic character of the wild-type protein. Cell Growth Differ 11: 185-190, 2000.

24. Ryan MJ, Didion SP, Mathur S, Faraci FM and Sigmund CD: Ppar(gamma) agonist rosiglitazone improves vascular function and lowers blood pressure in hypertensive transgenic mice. Hypertension 43: 661-666, 2004.

25. Shao J, Sheng H and DuBois RN: Peroxisome proliferatoractivated receptors modulate K-ras-mediated transformation of intestinal epithelial cells. Cancer Res 62: 3282-3288, 2002

26. Fauti T, Muller-Brusselbach S, Kreutzer M, Rieck M, Meissner W, Rapp U, Schweer H, Komhoff M and Muller R: Induction of pparbeta and prostacyclin (pgi2) synthesis by raf signaling: Failure of pgi2 to activate pparbeta. FEBS J 273: 170-179, 2006.

27. Burdick AD, Kim DJ, Peraza MA, Gonzalez FJ and Peters JM: The role of peroxisome proliferator-activated receptor-beta/delta in epithelial cell growth and differentiation. Cell Signal 18: 9-20, 2006.

28. Reed KR, Sansom OJ, Hayes AJ, Gescher AJ, Peters JM and Clarke AR: Ppardelta status and mismatch repair mediated neoplasia in the mouse intestine. BMC Cancer 6: 113, 2006.

29. Palakurthi SS, Aktas H, Grubissich LM, Mortensen RM and Halperin JA: Anticancer effects of thiazolidinediones are independent of peroxisome proliferator-activated receptor gamma and mediated by inhibition of translation initiation. Cancer Res 61: 6213-6218, 2001

30. Chawla A, Barak Y, Nagy L, Liao D, Tontonoz P and Evans RM: Ppar-gamma dependent and independent effects on macrophagegene expression in lipid metabolism and inflammation. Nat Med 7: 48-52, 2001.

31. Clay CE, Monjazeb A, Thorburn J, Chilton FH and High KP: 15-deoxy-delta12,14-prostaglandin $\mathrm{j} 2$-induced apoptosis does not require ppargamma in breast cancer cells. J Lipid Res 43: 1818-1828, 2002.

32. Nosjean O and Boutin JA: Natural ligands of ppargamma: are prostaglandin $j(2)$ derivatives really playing the part? Cell Signal 14: 573-583, 2002.

33. Baek SJ, Wilson LC, Hsi LC and Eling TE: Troglitazone, a peroxisome proliferator-activated receptor gamma (ppargamma) ligand, selectively induces the early growth response-1 gene independently of ppar gamma. A novel mechanism for its antitumorigenic activity. J Biol Chem 278: 5845-5853, 2003.

34. Laurora S, Pizzimenti S, Briatore F, Fraioli A, Maggio M, Reffo P, Ferretti C, Dianzani MU and Barrera G: Ppar ligands affect growth-related gene expression in human leukemic cells. J Pharmacol Exp Ther 305: 932-942, 2003.

35. Baek SJ, Kim JS, Nixon JB, Di Augustine RP and Eling TE: Expression of nag-1, a transforming growth factor-beta superfamily member, by troglitazone requires the early growth response gene egr-1. J Biol Chem 279: 6883-6892, 2004. 